\title{
Ag-ZSM-11 ZEOLITE SYNTHESIS USING SILICA FROM ELEPHANT GRASS FOR LED APPLICATION
}

\author{
Citra Deliana Dewi Sundari ${ }^{1}$, Soni Setiadji ${ }^{2}$, Atthar Luqman Ivansyah ${ }^{3}$, Dede \\ Abdurrahman $^{2}$ and Denia Febby Nurbaeti ${ }^{2}$ \\ 1Department of Chemistry Education, UIN Sunan Gunung Djati Bandung, Jl. Cimencrang, \\ Cimenerang, Panyileukan, Bandung, West Java, 40292, Indonesia \\ 2Department of Chemistry, Faculty of Science and Technology, UIN Sunan Gunung Djati Bandung, \\ Jl. A.H. Nasution No.105 Bandung, West Java, 40614, Indonesia \\ ${ }^{3}$ Master Program in Computational Science, Faculty of Mathematic and Natural Science, Institut \\ Teknologi Bandung, Jl.Ganesha No. 10, Bandung, West Java, 40132, Indonesia \\ *Email: citra@uinsgd.ac.id
}

\begin{abstract}
s
Silica $\left(\mathrm{SiO}_{2}\right)$ has been successfully isolated from elephant grass by the sol gel method through $p H$ regulation using $\mathrm{NaOH}$ and $\mathrm{HCl}$. The resulting silica has an amorphous character with crystalline phase impurities. The isolated silica was then used as a source of silica for the synthesis of ZSM-11 zeolite using the hydrothermal method with a ratio of $\mathrm{SiO}_{2}: \mathrm{TBAOH}: \mathrm{H}_{2} \mathrm{O}=1: 0.35: 25$. XRD characterization results confirmed the formation of ZSM-11 zeolite. The SEM results show that the ZSM-11 zeolite crystal morphology is oval with crystal growth in all directions. Immersion of the synthesized ZSM-11 zeolite into $\mathrm{AgNO}_{3}$ solution and followed by calcination resulted in zeolite Ag-ZSM-11 which has different optical properties compared to the initial ZSM-11 zeolite. Zeolite ZSM-11 gives purple luminescence while zeolite Ag-ZSM-11 gives pink luminescence when illuminated under UV lights.
\end{abstract}

Keywords: silica isolation; elephant grass; zeolite; ZSM-11; LED

\section{Introduction}

The use of sub-nanometer-sized precious metal clusters as luminescent materials has been reported by several researchers in the past few decades (Bhandari et al., 2016). Interest in this materials is caused by intense light absorption, efficient emissions, and bright color emissions. However, controlled synthesis and stabilization of clusters of one of the precious metals, i.e. silver, which is associated with excellent size, shape and electronic properties is still a challenge for scientists. To overcome this problem, several different synthetic approaches have been reported. Metal clusters can be stabilized by organic ligands such as small molecules (Zheng et al., 2002) or organic oligomers such as DNA (Temboury et al., 2016), acrylate 82

Copyright (C) 2018 WJC | ISSN 2621-5985 (online) | ISSN 2549-385X (print)

Volume 1, Nomor 2, 2018 
(Kunwar et al., 2014), and peptides (Yu et al., 2007), or by inorganic supporting materials such as glass (Royon et al., 2010). A different approach involves the synthesis of "ship-inbottle" where the growth of metal clusters is limited by the pore size of supporting materials such as zeolites (Coutino-Gonzalez et al., 2014).

Zeolite is a material that can be used as a host for silver clusters because $\mathrm{Ag}^{+}$ions can easily occupy zeolite cavities through cation exchange into zeolite pores, and also because of well-defined crystal porosity (Van Oers et al., 2014). Several studies that have been reported, have shown that emissions from Ag-zeolite are in the visible light spectrum (De Cremer et al., 2009) with external quantum efficiency approaching one (Fenwick et al., 2016). Therefore, its use as a next generation phosphor material in fluorescence lamps (Vosch et al., 2009) and as a wavelength converter in solar cells has been recommended by researchers (Vosch et al., $2009 \mathrm{~b}$ ). The main disadvantage of light emitting diode (LED) material that is commonly used today, both organic and inorganic, is its susceptibility to oxidation and aggregation, which results in the loss of character of the material emission (Schwabegger et al., 2014). The presence of Ag clusters in zeolite pores can prevent $\mathrm{Ag}$ aggregation, so that the Ag-zeolite material has the potential to be used as a light-emitting diode. Kennes et al reported for the first time, the first OLED with a silver cluster that was stable on the pore zeolite framework which acted as an effective emitter called ZEOLED (Kennes et al., 2017).

Zeolite synthesized by Kennes et al. and other researchers for the application of LED materials, still using commercial silica so that zeolite synthesis becomes relatively expensive. Therefore it is necessary to look for a substitute for commercial silica so that zeolite synthesis becomes cheaper. One of the alternative is to replace commercial silica with silica isolated from agricultural waste, one of which is rice husk waste. However, the use of rice husk waste as a source of silica for zeolite synthesis will compete with the use of rice husk waste for animal feed. Vaibhav et al. have reported that silica can be isolated from several plant parts such as rice husk, bamboo leaves, corn cobs, and peanut shells (Vaibhav et al., 2015). Nakanishi et al have reported that the content of silica $\left(\mathrm{SiO}_{2}\right)$ in elephant grass reaches $80 \%$. Silica isolated from elephant grass is amorphous (Nakanishi et al., 2016 \& 2014). Strezov et al. have reported that elephant grass can be converted thermally into bio-gas, bio-oil, and charcoal (Strezov et al., 2008). Srisittipokakun and Sangwaranatee have reported the physical and optical properties of glass synthesized using silica from elephant grass ash (Srisittipokakun et al., 2014). However, until now it is still rare for researchers to use silica isolated from elephant grass as a source of silica for zeolite synthesis. On the other hand, Kennes et al. (2017) reported the use of LTA type zeolite for ZEOLED applications by inserting $\mathrm{Ag}^{+}$ions into the zeolite pore. Until now no researcher has used other types of zeolite other than the type of LTA to synthesize Ag-Zeolite as a ZEOLED material. In this research, Ag-zeolite material has been synthesized using ZSM-11 Zeolite where the source of silica used is derived from elephant grass. 


\section{Methodology}

Chemicals used in this research was $\mathrm{HCl}\left(37 \%\right.$, $\left.\mathrm{Merck}^{\circledR}\right), \mathrm{NaOH}\left(\mathrm{Merck}^{\circledR}\right)$, TBAOH $\left(\operatorname{Merck}^{\circledR}\right), \mathrm{AgNO}_{3}\left(\operatorname{Merck}^{\circledR}\right)$, and Aqua DM.

\section{Silica Isolation from Elephant Grass}

Elephant grass leaves are washed thoroughly and dried in an oven at $110{ }^{\circ} \mathrm{C}$. The dried elephant grass is then burned by using the furnace at a temperature of $550{ }^{\circ} \mathrm{C}$ for 5 hours to remove organic substances. The ash obtained is dissolved with $1 \mathrm{M} \mathrm{NaOH}$ solution which is accompanied by heating at a temperature of $150{ }^{\circ} \mathrm{C}$ and stirring for 1 hour followed by the filtration. Then $3 \mathrm{M} \mathrm{HCl}$ solution is added dropwise to the filtrate solution until the $\mathrm{pH}$ of the filtrate solution becomes neutral, then left to stand overnight. The gel formed is then washed with hot aqua $\mathrm{DM}$ and dried in an oven at a temperature of $110{ }^{\circ} \mathrm{C}$ for 24 hours.

\section{Zeolite ZSM-11 Synthesis}

TBAOH is pipetted and put into a polypropylene (pp) container and stirred using a magnetic stirrer, then silica and water are added in succession and done slowly. After stirring for 3 hours at a constant speed, the solution is left overnight for the aging process. After the aging process, the mixture is put into an autoclave and put in the oven for 2 days at $170{ }^{\circ} \mathrm{C}$. The residue is filtered and washed using aqua until the $\mathrm{pH}$ of the filtrate is neutral. The residue is then dried in an oven for 12 hours at $100{ }^{\circ} \mathrm{C}$ and then calcined at $600{ }^{\circ} \mathrm{C}$ for 4 hours. Crystallinity and morphology of zeolites were measured by X-ray diffractometer (XRD) and Scanning Electron Microscope (SEM). Silica content from the leaves of elephant grass was measured by X-Ray Fluorence (XRF).

Synthesis and characterization of Zeolite AgZSM-11 as a ZEOLED material

The principle of synthesizing Ag-ZSM11 zeolite is by inserting $\mathrm{Ag}^{+}$ions into the ZSM-11 zeolite pores. The strategy is to mix Zeolite ZSM-11 into a certain concentration of $\mathrm{AgNO}_{3}$ and stir it for several hours. Then filtered using a vacuum pump accompanied by washing with aqua DM several times, and the residue was separated. The residue obtained in the form of Ag-ZSM-11 zeolite was then dried in an oven at a temperature of $110{ }^{\circ} \mathrm{C}$ for 24 hours. Furthermore, to eliminate the possible organic impurities in zeolite, calcination was carried out using a furnace at a temperature of $550{ }^{\circ} \mathrm{C}$ for 5 hours. Ag-ZSM-11 zeolite was then placed under a UV lamp to see the color of luminescence and was characterized by a photoluminescence spectrophotometer.

\section{Results and Dicussions}

Silica Isolation from Elephant Grass Leaves (Pennisetum purpureum)

Silica in elephant grass leaves (Pennisetum purpureum) was isolated using alkali precipitation method. The isolated silica was characterized by XRF, XRD, and FT-IR. Table 1 shows the results of XRF which gives information about the content of the oxide minerals in silica isolated from elephant grass.

The crystallinity of silica isolated from the leaves of elephant grass was analyzed using XRD whose results can be seen in Figure 1. There is a widening of the peak at 20.37-24.8 ${ }^{\circ}$ with the highest peak at $2 \theta=$ 
$21.7^{\circ}$. This shows that the silica from the isolation has an amorphous phase formed due to the presence of silanol ( $\mathrm{Si}-\mathrm{OH}$ ) groups on its surface (Shim et al., 2015). However, the presence of peaks at $2 \theta=30.38^{\circ}, 31.45^{\circ}$ and $44.31^{\circ}$ indicates that crystalline $\mathrm{SiO}_{2}$ phase was also formed as an impurity (Shim et al., 2015).

Table 1. Results of characterization of silica from elephant grass leaves using XRF

\begin{tabular}{llll}
\hline Oxides & $\begin{array}{c}\text { Quantity } \\
(\%)\end{array}$ & Elements & $\begin{array}{c}\text { Quantity } \\
(\%)\end{array}$ \\
\hline $\mathrm{SiO}_{2}$ & 86.33 & $\mathrm{Si}$ & 40.36 \\
$\mathrm{Al}_{2} \mathrm{O}_{3}$ & 0.154 & $\mathrm{Al}$ & 0.0814 \\
$\mathrm{CaO}$ & 0.184 & $\mathrm{Ca}$ & 0.132 \\
$\mathrm{MgO}$ & 0.0743 & $\mathrm{Mg}$ & 0.0448 \\
$\mathrm{Na}_{2} \mathrm{O}$ & 1.61 & $\mathrm{Na}$ & 1.2 \\
$\mathrm{Fe}_{2} \mathrm{O}_{3}$ & 0.018 & $\mathrm{Fe}$ & 0.0126 \\
$\mathrm{MnO} \mathrm{N}$ & - & $\mathrm{Mn}$ & - \\
\hline
\end{tabular}

To find out the bond vibrations of the isolated silica, FT-IR analysis was performed. The results of silica analysis with FT-IR shown in Figure 2 indicate a peak at wave number $514 \mathrm{~cm}^{-1}, 663 \mathrm{~cm}^{-1}, 805 \mathrm{~cm}^{-1}, 984 \mathrm{~cm}^{-}$ $1,1195 \mathrm{~cm}^{-1}$ and $1641 \mathrm{~cm}^{-1}$. Vibration at wave number $1641 \mathrm{~cm}^{-1}$ shows the vibration of $\mathrm{H}_{2} \mathrm{O}$ or $\mathrm{Si}-\mathrm{OH}$ molecules which are reactive groups on the surface of amorphous silica (Mozgawa et al., 2011).

The silanol group is a reactive group located on the surface of amorphous silica. In addition to indicating the presence of silanol groups, the wave number also indicates that there is still a water content in the isolated silica. The wave number $984 \mathrm{~cm}^{-1}$ indicates the vibration of the Si-O-Si bond (Lu et al., 2014).

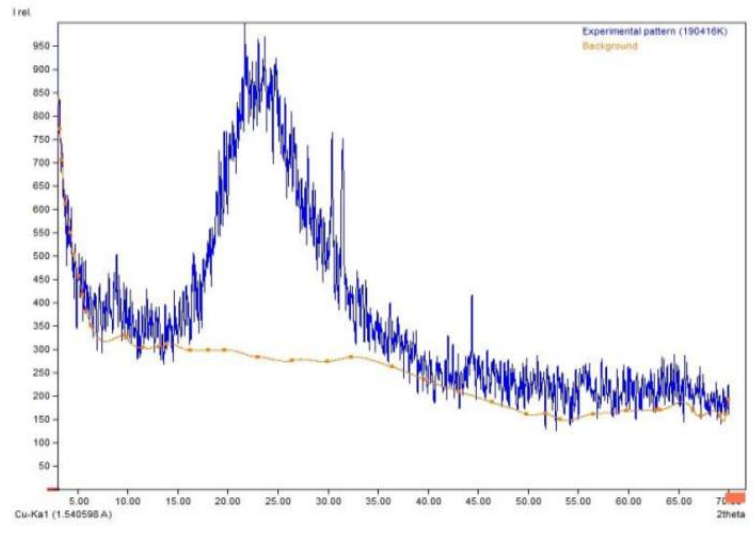

Figure 1 Difffractogram of Silica isolated from Elephant Grass

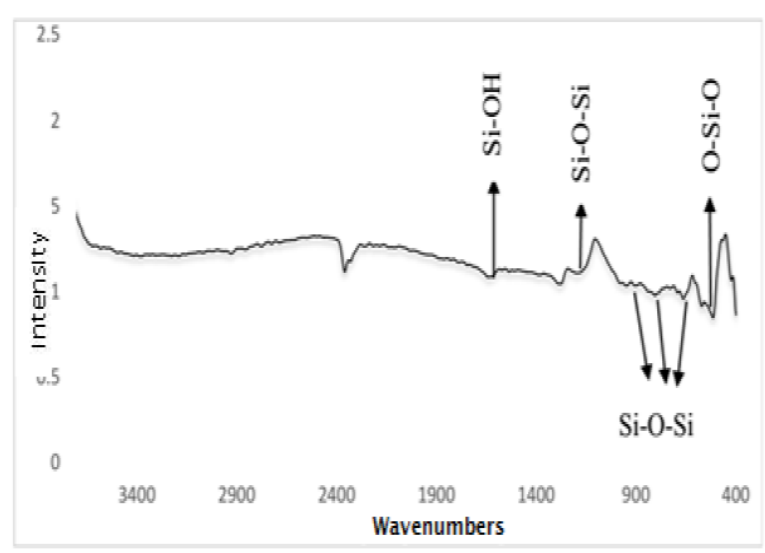

Figure 2 FT-IR spectrum of silica isolated from elephant grass

Synthesis and Characterization of ZSM-11 Zeolite

ZSM-11 zeolite synthesis utilized $\mathrm{TBAOH}$ as template and silica derived from 
elephant grass leaves. TBAOH will direct the filling of spaces in the structure of zeolites by $\mathrm{Si}$ and $\mathrm{O}$ so that later a ring will form which consists of $\mathrm{SiO}_{2}$ tetrahedra and forms a crystal lattice in the form of D5R (consisting of 10 rings). After zeolite is formed, then it is characterized using XRD.

Figure 3 is a diffractogram of ZSM-11 zeolite synthesized in this study which is compared with the IZA (International Zeolite Association) database. In addition, the diffractogram of the experimental results was also compared with the journal written by Lu et al., where the specific diffractogram peak that indicates a ZSM-11 Zeolite has been formed at $2 \theta=7.92^{\circ}, 8.78^{\circ}, 23.14^{\circ}, 23.98^{\circ}$, and $45.21^{\circ}$ (Lu et al., 2014), Based on the diffractogram shown in Figure 3 , there is a peak at $2 \theta=7.93^{\circ}, 8.85^{\circ}, 23.11^{\circ}, 23.96^{\circ}$, and $45.05^{\circ}$. Thus it can be concluded that ZSM-11 Zeolite was formed in this study. The presence of two peaks at $2 \theta$ between $23-25^{\circ}$ and one peak at $45.4^{\circ}$ indicates that in the synthesized ZSM-11 zeolite there is no ZSM-5 zeolite phase.

SEM image the synthesized ZSM-11 synthesis can be seen in Figure 4. From Figure 4 it can be seen that the synthesized ZSM-11 zeolite has an oval shape with a fairly pointed tip and crystal growth in various directions. It can be seen in figure (a) that the overall shape of zeolite has been evenly distributed with the same size. This morphology is different when compared to the ZSM-11 zeolite synthesized by Lu et al. (Lu et al., 2014). In ZSM-11 zeolites synthesized by Lu, et al. showing morphology with an oval shape that is not too sharp at the edges. This difference occurs because of differences in the source of silica used, the mole ratio, and the temperature at stirring and incubation, as well as the length of incubation time.

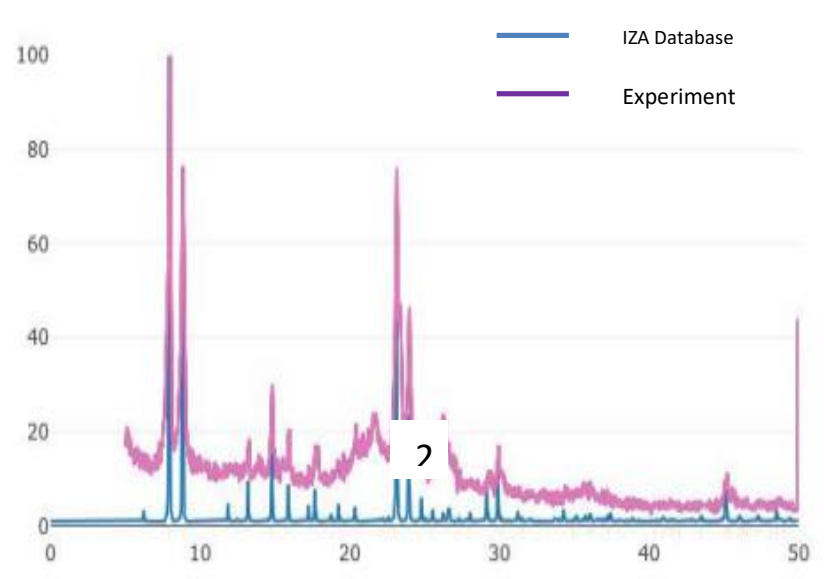

Figure 3 Diffractogram of ZSM-11 Zeolite

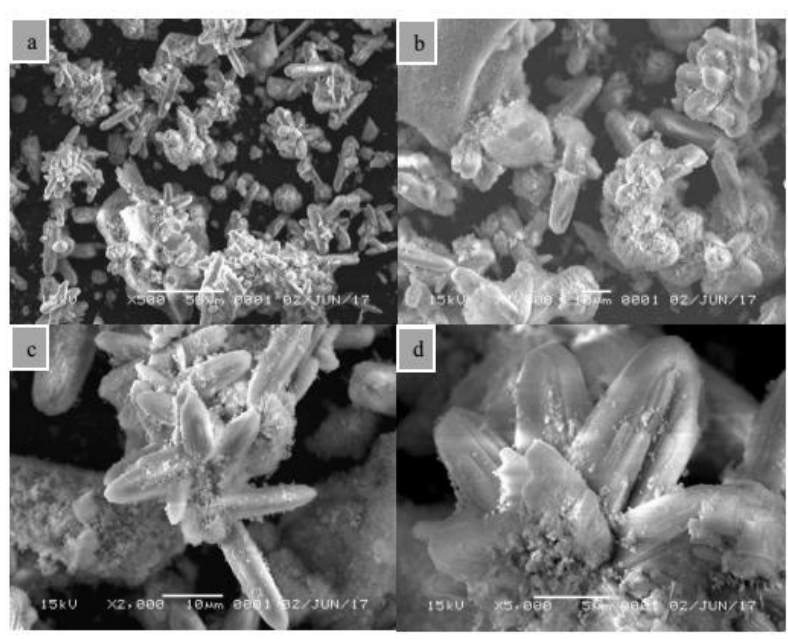

Figure 4 ZSM-11 Zeolite SEM Test Results (a) 500x; (b) 1000x; (c) 2000x; (d) 5000x magnification.

Figure 5 shows the results of zeolite analysis of ZSM-11 using FTIR. FTIR analysis was carried out at wavenumber $1700-400 \mathrm{~cm}^{-}$ 1 , the wavenumber range is the fingerprint 
region to show what functional groups it contains. At wavenumber of $495.687 \mathrm{~cm}^{-1}$ is a bending vibration $\mathrm{TO}_{4} \quad(\mathrm{~T}=\mathrm{Si})$. At wavenumber of 526.743 and $1220.926 \mathrm{~cm}^{-1}$ it is a double 5-ring (D5R) bending vibration in the ZSM-11 zeolite structure. This double 5ring is an external link between one zeolite layer and another. At wavenumber of 811.090 and $1021.146 \mathrm{~cm}^{-1}$ it is stretching vibration of Si-O-Si (Dey et al., 2012 \& Zhang et al., 2012).

Synthesis and Characterization of Ag-ZSM-11 Zeolite

ZSM-11 zeolite was immersed into $\mathrm{AgNO}_{3}$ solution. This will cause $\mathrm{Ag}^{+}$ions to enter the pores of ZSM-11 zeolite, forming the Ag-ZSM-11 zeolite. The optical properties related to the application of LEDs possessed by ZSM-11 and Ag-ZSM-11 have differences in luminescence when illuminated by UV lamps as shown in Figure 6.

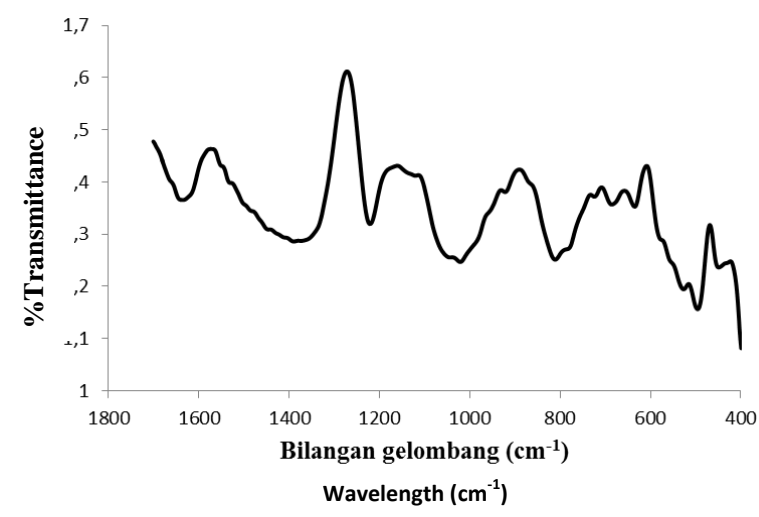

Figure 5 FT-IR spectrum of the synthesized ZSM-11 Zeolite

When the ZSM-11 zeolite was illuminated by a UV lamp, it produced a purple glow. However, when Ag-ZSM-11 zeolite is illuminated by UV light, pink luminescence is produced. ZSM-11 zeolite is an insulator so that the energy gap between the valence band and conduction band is relatively high. As a result, electronic transfers between orbitals will be relatively difficult to occur when illuminated by UV lamps and the luminescent of ZSM-11 zeolite will be purple, the same color as the UV light used. However, the presence of $\mathrm{Ag}^{+}$ions in the ZSM-11 zeolite pore will make the difference in the energy gap between the valence band and the conduction band smaller than the initial zeolite before immersed in $\mathrm{Ag}^{+}$ solution. As a result, UV light emitted by UV lamps will be absorbed by Ag-ZSM-11 zeolite for electron transfer between orbitals (from the valence band to the conduction band), because the transfer of electrons between orbitals in Ag-ZSM-11 zeolite is relatively easier when compared with electron transfer between orbitals on ZSM-11 zeolites due to differences in the energy gap between the valence band and the conduction band. The transfer of electrons in Ag-ZSM-11 zeolite is proven by the presence of peaks at wavelengths around $500-600 \mathrm{~nm}$ in the photoluminescence (PL) spectrum. 


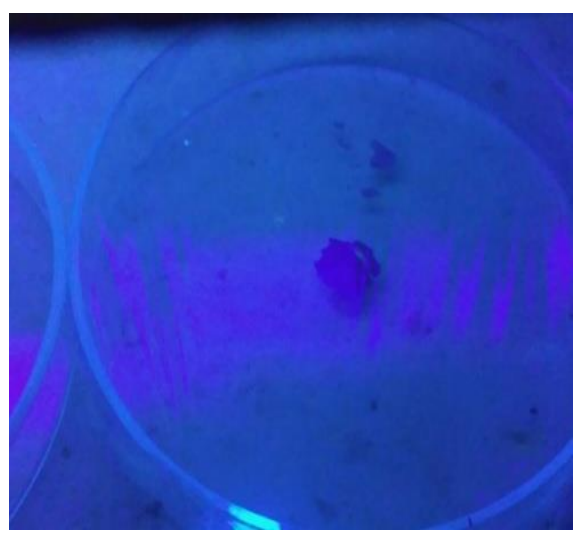

(a)

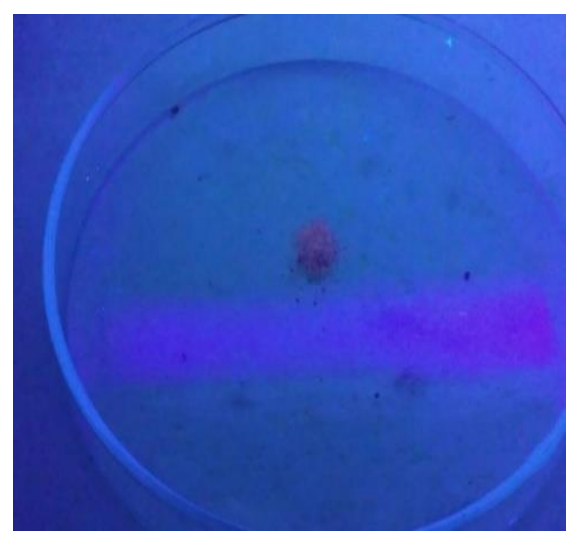

(b)

Figure 6 (a) ZSM-11 Zeolite luminescence when illuminated by UV lights; (b) Zeolite Ag-ZSM-11 luminescence when illuminated by UV lamps

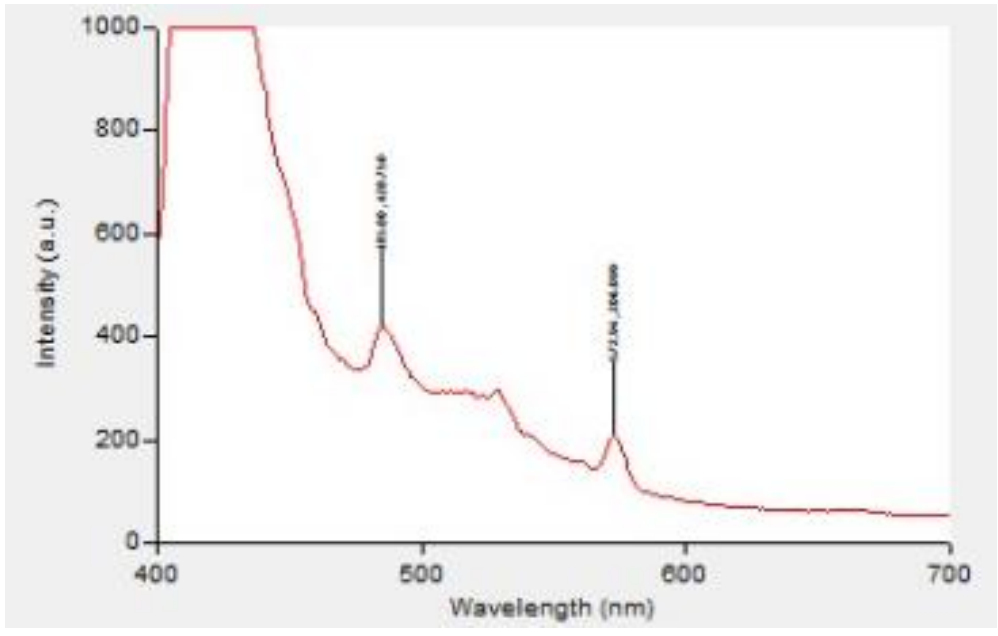

Figure 7 Photoluminescence spectrum of Ag-ZSM-11 zeolite

\section{Conclusion}

Silica can be isolated from elephant grass with $\mathrm{SiO}_{2}$ content of $86.33 \% \mathrm{w} / \mathrm{w}$. Silica isolated from elephant grass has amorphous properties accompanied by the presence of other crystalline silica impurities. From the results of XRD characterization, silica isolated from elephant grass was proven to be used as a source of silica for the synthesis of ZSM-11 zeolite. ZSM-11 zeolite synthesized with silica isolated from elephant grass has an oval shape and crystalline growth in all directions. Mixing ZSM-11 zeolite into $\mathrm{AgNO}_{3}$ solution, making $\mathrm{Ag}^{+}$ions into the zeolite pore and forming $\mathrm{Ag}$ 88 
ZSM-11 zeolite. ZSM-11 and Ag-ZSM-11 zeolites have different optical properties related to LEDs when illuminated by UV lights, ZSM-11 zeolites produce purple luminescence while Ag-ZSM-11 zeolite produces pink luminescence.

\section{References}

Bhandari, S., Pramanik, S., Khandelia, R., Chattopadhyay, A.. 2016. Gold Nanocluster and Quantum Dot Complex in Protein for Biofriendly White-Light-Emitting Material. ACS Appl. Mater. Interfaces. 8, 1600.

Zheng, J., Dickson, R. M.. 2002. Individual Water-Soluble Dendrimer-Encapsulated Silver Nanodot Fluorescence. J. Am. Chem. Soc. $124,13982$.

Temboury, M. R. C., Paolucci, V., Hooley, E. N., Latterini, L., Vosch, T.. 2016. Probing DNAstabilized fluorescent silver nanocluster spectral heterogeneity by time-correlated single photon counting. Analyst. 141(1), 123.

Kunwar, P., Hassinen, J., Bautista, G., Ras, R. H. A., Toivonen, J. 2014. Direct Laser Writing of Photostable Fluorescent Silver Nanoclusters in Polymer Films. ACS Nano. 8 (11), 11165-71.

Yu, J., Patel, S. A., Dickson, R. M. 2007. In vitro and intracellular production of peptideencapsulated fluorescent silver nanoclusters. Angew. Chem. Int. Ed. 46 (12), 2028-30.

Royon, A., Bourhis, K., Bellec, M., Papon, G., Bousquet, B., Deshayes, Y., Cardinal, T., Canioni, L. 2010. Silver clusters embedded in glass as a perennial high capacity optical recording medium. Adv. Mater. 22 (46), 5282-6.
Coutino-Gonzalez, E., Grandjean, D., Roeffaers, M., Kvashnina, K., Fron, E., Dieu, B., De Cremer, G., Lievens,P., Sels, B., Hofkens, J. 2014. X-ray irradiation-induced formation of luminescent silver clusters in nanoporous matrices. Chem. Commun. 50 (11), 1350-2.

Van Oers, C. J., Kurttepeli, M., Mertens, M., Bals, S., Meynen, V., Cool, P. 2014. Zeolite $\beta$ nanoparticles based bimodal structures: Mechanism and tuning of the porosity and zeolitic properties. Microporous Mesoporous Mater. 185, 204-212.

De Cremer, G., Coutiño-Gonzalez, E., Roeffaers, M. B. J., Moens, B., Ollevier, J., Van der Auweraer, M., Schoonheydt, R., Jacobs, P. a., De Schryver, F. C., Hofkens, J., De Vos, D. E., Sels, B. F., Vosch, T. 2009. Characterization of fluorescence in heat-treated silverexchanged zeolites. J. Am. Chem. Soc. 131 (8), 3049-56.

Fenwick, O., Coutino-Gonzalez, E., Grandjean, D., Baekelant, W., Richard, F., Bonacchi, S., De Vos, D., Lievens, P., Roeffaers, M., Hofkens, J., Samori, P. 2016. Tuning the energetics and tailoring the optical properties of silver clusters confined in zeolites. Nat. Mater. 15(9), 1017-22.

Vosch, T., Sels, B. F., Roeffaers, M. B. J., Hofkens, J., De Vos, D. E., De Cremer, G. 2009. BE2008/0050 (WO 2009006707).

Vosch, T., Sels, B. F., Roeffaers, M. B. J., Hofkens, J., De Vos, D. E., De Cremer, G. 2009. BE2008/0051 (WO 2009006707).b

Schwabegger, G., Dingemans, T., Resel, R., Sitter, H., Simbrunner, C. 2014. Non-doped, blue-emitting, color-stable, organic lightemitting diode based on 2,2' : 6',2' ternaphthalene. Appl. Phys. A: Mater. Sci. Process. 115 (3), 731-35. 
Kennes, K., Coutino-Gonzalez, E., Martin, C., Baekelant, W., Roeffaers, M.B. J., Van der Auweraer, M. 2017. Silver Zeolite Composites-Based LEDs: A Novel SolidState Lighting Approach. Adv. Funct. Mater. 27 (14), 1606411.

Vaibhav, V., Vijayalakshmi, U., Roopan, S. M. 2015. Agricultural waste as a source for the production of silica nanoparticles. Spectrochimica Acta Part A: Molecular and Biomolecular Spectroscopy. 139, 515.

Nakanishi, E.Y., Frías, M., Martínez-Ramírez, S., Santos, S. F., Rodrigues, M. S., Rodríguez, O., Savastano Jr., H. 2014. Characterization and properties of elephant grass ashes as supplementary cementing material in pozzolan/Ca(OH $)_{2}$ pastes. Construction and Building Materials. 73, 391.

Nakanishi, E. Y., Frías, M., Santos, S. F., Rodrigues, M. S., de la Villa, R. V., Rodriguez, O., Junior, H. S. 2016. Investigating the possible usage of elephant grass ash to manufacture the ecofriendly binary cements. J. Clean. Prod. 116, 236-43.

Strezov V., Evans T. J., Hayman C. 2008. Thermal conversion of elephant grass (Pennisetum Purpureum Schum) to biogas, bio-oil and charcoal. Bioresource Technology. 99, 8394-8399.

Srisittipokakun, N., Sangwaranatee, N. 2014. Comparative Study of Physical and Optical Properties of Glasses from $\mathrm{SiO}_{2}$ and Napier Ash. Adv. Mat. Res. 979, 401.

Shim, J., Velmurugan, P., Oh, B-T. 2015. Extraction and physical characterization of amorphous silica made from corn cob ash at variable $\mathrm{pH}$ conditions via sol gel processing. J. Indust. Eng. Chem. 30, 24953.
Mozgawa, W., Krol, M., and Barczyk, K. 2011. FT-IR Studies of Zeolites from Different Structural Groups. Chemik, 65 (7), 667674.

Lu, M., Cheng, Y., Pan, S.-l., Wei, G.-y. 2014. Des. Wat. Treat. 57, 1.

Dey, K. P., Gosh, S., Naskar, M. K. 2012. A facile synthesis of ZSM-11 zeolite particles using rice husk ash as silica source. Mat. Lett. 87, 87-89.

Zhang, L., Liu, S., Xie, S., Xu, L. 2012. Organic template-free synthesis of ZSM-5/ZSM-11 co-crystalline zeolite. Mic. Mes. Mat. 147, 117. 